\title{
DETERMINANTES SOCIOECONÓMICOS DEL RECICLAJE EN LA PAZ, BOLIVIA: UN ANÁLISIS DE POLÍTICA PÚBLICA
}

\section{María del Pilar Osorio Borrero}

\section{RESUMEN}

Se realiza el análisis de factores determinantes en la probabilidad de reciclar en la ciudad de La Paz mediante información de la Encuesta de Hogares del Gobierno Autónomo Municipal de La Paz 2016. El estudio identifica las variables socioeconómicas que tienen mayor efecto en la probabilidad de reciclar a través de un modelo Probit. Así mismo, se evalúa el impacto de la implementación de los puntos verdes de recolección de material de reciclaje en la ciudad, como estrategia de política pública ambiental a través de la estimación de la distancia como vínculo del programa y la decisión de reciclar, comprobando los efectos de política mediante estimaciones econométricas de matching, estimadores de interacciones de variables y modelos semiparamétricos.

Palabras Clave: Reciclaje, Política Pública, Evaluación de Impacto.

DOI: 10.23881/idupbo.019.2-4e 